\title{
Porphyria Mimic: A Note of Caution
}

\author{
Joseph Valamparampil ${ }^{1,2} \cdot$ Chayarani Kelgeri $^{2,3} \cdot$ Mukul Vij $^{1} \cdot$ Ashwin Rammohan ${ }^{1} \odot \cdot$ Naresh Shanmugam ${ }^{1}$. \\ Mohamed Rela ${ }^{1}$
}

Received: 10 May 2021 / Accepted: 13 July 2021 / Published online: 13 August 2021

๑) Dr. K C Chaudhuri Foundation 2021

To the Editor: A 5-y-old male child was brought for evaluation of liver disease. He was diagnosed with hereditary tyrosinemia-1 (HT-1) at the age of $3 \mathrm{y}$ and started on 2-(2-nitro-4-trifluoromethylbenzoyl)-1,3-cyclohexanedione (NTBC). Since NTBC was expensive and the supply was erratic, he was not compliant with the medication. While being evaluated, he developed generalized seizures, bilateral lower limb paralysis, and systemic hypertension. Since all the features were suggestive of neurologic crisis of HT-1, NTBC was urgently restarted. Metabolic profile sent during the crisis showed elevated urinary succinylacetone and porphyrin levels with absent porphobilinogen (PBG) synthase activity. He recovered over the next $10 \mathrm{~d}$ without any residual neurological sequelae. The child underwent liver transplantation (LT) 1 mo later and remains well with stable graft function on 3-y-follow-up.

Neurologic crises are a hallmark of untreated tyrosinemia with high risk of morbidity and mortality $[1,2]$. It is often missed and the incidence can be as high as $42 \%$ of all untreated patients $[2,3]$. Clinical presentation of neurologic crisis can be mistaken as meningismus, opisthotonus, or porphyria due to an interrelationship between tyrosine catabolism and heme biosynthesis. Succinylacetone accumulates due to a deficiency of fumarylacetoacetate hydrolase (FAH) deficiency and inhibits the synthesis of porphobilinogen from $\delta$-aminolevulinic acid ( $\delta$-ALA) by inhibiting porphyrin synthetic enzyme $\delta$-ALA dehydratase $[1,2]$. $\delta$-ALA accumulation causes the clinical signs of neurologic crises.

Ashwin Rammohan

ashwinrammohan@gmail.com

$1 \quad$ Institute of Liver Disease and Transplantation, Dr Rela Institute and Medical Centre, Bharath Institute of Higher Education and Research, Chennai, Tamil Nadu 600044, India

2 The Liver Unit, Birmingham Children's Hospital, Birmingham, UK

3 Gleneagles Global Health City, Chennai, Tamil Nadu, India
In our unit, 8 children underwent LT for HT-1 from 2010 to 2019 , all of whom remain well on a median follow-up of 72 mo (16-124 mo). Six (75\%) were initiated on NTBC, but opted for LT since they could not afford the medications or could not ensure an adequate supply over time. Though lifesaving and helps avoid LT, NTBC is expensive and difficult to procure and should only be initiated if a constant supply is guaranteed and therapeutic drug level monitoring is possible.

\section{Declarations}

Conflict of Interest None.

\section{References}

1. Chinsky JM, Singh R, Ficicioglu C, et al. Diagnosis and treatment of tyrosinemia type I: a US and Canadian consensus group review and recommendations. Genet Med. 2017;19. https://doi.org/10. 1038/gim.2017.101

2. Mitchell G, Russo P, Dubois J, Alvarez F. Tyrosinemia. In: Liver disease in children $4^{\text {th }}$ ed. Suchy FJ et al. (eds). Cambridge: Cambridge Univ. Press; 2014. p. 526-45.

3. Schlump JU, Perot C, Ketteler K, et al. Severe neurological crisis in a patient with hereditary tyrosinaemia type I after interruption of NTBC treatment. J Inherit Metab Dis. 2008;31(Suppl 2):S223-5.

Publisher's Note Springer Nature remains neutral with regard to jurisdictional claims in published maps and institutional affiliations. 